九州大学学術情報リポジトリ

Kyushu University Institutional Repository

\title{
Comparison between Richards Growth Function, its Family Growth Functions and Basic Growth Function
}

\section{Shimojo, Masataka}

Laboratory of Regulation in Metabolism and Behavior, Division of Animal and Marine Bioresource Sciences, Department of Bioresource Sciences, Faculty of Agriculture, Kyushu University and Department of Grassland and Forage Science, College of Animal Sciences and Technology, Nanjing Agricultural University

Nakano, Yutaka

University Farm, Faculty of Agriculture, Kyushu University

Tobisa, Manabu

Faculty of Agriculture, Miyazaki University

Shao, Tao

Laboratory of Regulation in Metabolism and Behavior, Division of Animal and Marine Bioresource Sciences, Department of Bioresource Sciences, Faculty of Agriculture, Kyushu University and Department of Grassland and Forage Science, College of Animal Sciences and Technology, Nanjing Agricultural University

https://doi.org/10.5109/19641

出版情報: 九州大学大学院農学研究院紀要. 56 (1)，pp.75-76，2011-02. Faculty of Agriculture， Kyushu University

バージョン :

権利関係 : 


\title{
Comparison between Richards Growth Function, its Family Growth Functions and Basic Growth Function
}

\author{
Masataka SHIMOJO*, Yutaka NAKANO ${ }^{1}$, Manabu TOBISA ${ }^{2}$ and Tao SHAO \\ Laboratory of Regulation in Metabolism and Behavior, Division of Animal and Marine Bioresource Sciences, \\ Department of Bioresource Sciences, Faculty of Agriculture, Kyushu University, Fukuoka 812-8581, \\ Japan and Department of Grassland and Forage Science, College of Animal Sciences and Technology, \\ Nanjing Agricultural University, Weigang 1, Nanjing 210095, the People's Republic of China \\ (Received October 29, 2010 and accepted November 8, 2010)
}

\begin{abstract}
This study was designed to make a comparison between Richards growth function, its family growth functions and basic growth function. Each growth function was combined with its first and second derivatives. The results obtained were as follows. Mitscherlich, logistic and Gompertz growth functions, each of which was a special case of Richards growth function, took a common form when combined with first and second derivatives. In the case of Richards growth function, there was an additional $m$ when compared with the common form. The present study showed that Richards growth function resulted in its family growth functions when $m=0$, and collapsed into basic growth function when $m=1$. These were contradictory to the results by Richards (1959), except Mitscherlich growth function that was given when $m=0$. There was a gap impossible to jump over between basic growth function and each of Mitscherlich, logistic and Gompertz growth functions. It was suggested that Richards growth function existed between a group of its family growth functions and basic growth function.
\end{abstract}

\section{INTRODUCTION}

Basic growth function gives an exponential increase only (Blackman, 1919), but the actual growth curve is given by functions with inflection point and asymptote. Richards growth function, which is flexible in the position of inflection point, is considered a generalized function to Mitscherlich, logistic and Gompertz growth functions (Richards, 1959; Osumi and Ishikawa, 1983). Attempts were made to relate basic growth function with logistic growth function (Shimojo et al., 2009) and with Richards growth function (Shimojo et al., 2010) to compare mathematical properties.

The present study was designed to make a comparison between Richards growth function, its family growth functions and basic growth function.

\section{COMPARING RICHARDS GROWTH FUNCTION WITH ITS FAMILY GROWTH FUNCTIONS AND BASIC GROWTH FUNCTION}

\section{Dynamics of Richards growth function} by

Richards growth function (Richards, 1959) is given

$$
W_{\mathbf{R}}=A \cdot(1-b \cdot \exp (-k \cdot t))^{1 /(1-m)}
$$

where $A, b, k$ and $m$ are constants, $m \neq 1, t=$ time.

Combining function (1) with its first and second derivatives gives

\footnotetext{
1 University Farm, Faculty of Agriculture, Kyushu University, Kasuya, Fukuoka 811-2307

2 Faculty of Agriculture, Miyazaki University, Miyazaki 889-2192, Japan

* Corresponding Author (E-mail: mshimojo@agr.kyushu-u.ac.jp)
}

$$
\begin{aligned}
& \left(d W_{\mathbf{R}} / d t\right)^{2} \\
& =W_{\mathbf{R}} \cdot\left(d^{2} W_{\mathbf{R}} / d t^{2}\right) \cdot((b \cdot \exp (-k \cdot t)) /(b \cdot \exp (-k \cdot t) \\
& \quad-1+m)) .
\end{aligned}
$$

where $m \neq 1$.

\section{Dynamics of Mitscherlich growth function}

Mitscherlich growth function (Richards, 1959; Osumi and Ishikawa, 1983) is given by

$$
W_{\mathbf{M}}=A \cdot(1-b \cdot \exp (-k \cdot t))
$$

where $A, b$, and $k$ are constants, $t=$ time.

Combining function (3) with its first and second derivatives gives

$$
\begin{aligned}
& \left(d W_{\mathbf{M}} / d t\right)^{2} \\
& =W_{\mathbf{M}} \cdot\left(d^{2} W_{\mathbf{M}} / d t^{2}\right) \cdot((b \cdot \exp (-k \cdot t)) /(b \cdot \exp (-k \cdot t)-1)) .
\end{aligned}
$$

\section{Dynamics of logistic growth function}

Logistic growth function (Richards, 1959; Osumi and Ishikawa, 1983) is given by

$$
W_{\mathbf{L}}=A /(1+b \cdot \exp (-k \cdot t))
$$

where $A, b$, and $k$ are constants, $t=$ time.

Combining function (5) with its first and second derivatives gives

$$
\begin{aligned}
& \left(d W_{\mathbf{L}} / d t\right)^{2} \\
& =W_{\mathbf{L}} \cdot\left(d^{2} W_{\mathbf{L}} / d t^{2}\right) \cdot((b \cdot \exp (-k \cdot t)) /(b \cdot \exp (-k \cdot t)-1)) .
\end{aligned}
$$

\section{Dynamics of Gompertz growth function}

Gompertz growth function (Richards, 1959; Osumi 
and Ishikawa, 1983) is given by

$$
W_{\mathbf{G}}=A \cdot \exp (-b \cdot \exp (-k \cdot t))
$$

where $A, b$, and $k$ are constants, $t=$ time.

Combining function (7) with its first and second derivatives gives

$$
\begin{aligned}
& \left(d W_{\mathbf{G}} / d t\right)^{2} \\
& =W_{\mathbf{G}} \cdot\left(d^{2} W_{\mathbf{G}} / d t^{2}\right) \cdot((b \cdot \exp (-k \cdot t)) /(b \cdot \exp (-k \cdot t)-1)) .
\end{aligned}
$$

\section{Dynamics of basic growth function}

Basic growth function is given by

$$
W_{\mathbf{B}}=W_{\mathbf{0}} \cdot \exp (r \cdot t)
$$

Where $W_{0}=$ weight at $t=0, r=$ relative growth rate, $t=$ time.

Combining function (9) with its first and second derivatives gives

$$
\left(d W_{\mathbf{B}} / d t\right)^{2}=W_{\mathbf{B}} \cdot\left(d^{2} W_{\mathbf{B}} / d t^{2}\right) .
$$

\section{Comparing Richards growth function with its fam-} ily growth functions and basic growth function

Equation (2), a generalized form of equations (4), (6) and (8), has an additional $m$ in the denominator. There is a singularity $(m=1)$ in equation (1). This singularity, boldly writing at the risk of making mistakes, seems to disappear in equation (2).

If $m=1$, then equation (2) results in equation (10), a collapse of Richards growth function (1) into basic growth function (9) (Shimojo et al., 2010). However, Richards (1959) shows that Richards growth function (1) tends to Gompertz growth function (7) as $m$ tends to 1 . This contradictory problem might be solved by the following explanation. Richards growth function is derived from the integration of differential equation (11) for the animal (Richards, 1959),

$$
d W / d t=\eta \cdot W^{m}-x \cdot W,
$$

where $\eta=$ constant of anabolism, $\boldsymbol{x}=$ constant of catabolism.

When $m=1$, equation (11) results in equation (12), whose form is equal to equation (13) from which basic growth function (9) is derived,

$$
d W / d t=(\eta-\varkappa) \cdot W, \quad(12) \quad d W / d t=r \cdot W .
$$

However, how Richards growth function breaks down to basic growth function remains to be investigated.

The present study shows that when $m=0$, equation
(2) results in equations (4), (6) and (8), from which Mitscherlich, logistic and Gompertz growth functions are derived, respectively. Although growth functions (3), (5) and (7) take different forms, corresponding equations (4), (6) and (8) take the same form when growth function is combined with its first and second derivatives. One of the reasons of these mathematical phenomena might be ascribed to the application of equation (10), an extended differential equation for basic growth function, to Richards growth function and its family growth functions when combined with first and second derivatives. The present results are also contradictory to the results by Richards (1959) and Osumi and Ishikawa (1983), except Mitscherlich growth function that is given when $m=0$. There is a gap, which is impossible to jump over due to the inequality (14), between basic growth function and each of Mitscherlich, logistic and Gompertz growth functions,

$$
b \cdot \exp (-k \cdot t) \neq b \cdot \exp (-k \cdot t)-1 \text {. }
$$

Further investigation is required to solve the contradictory problems between the results by Richards (1959) and the present results.

\section{Conclusions}

It is suggested from the present study that Richards growth function exists between a group of its family growth functions and basic growth function.

\section{ACKNOWLEDGEMENTS}

This study was supported by a Grant-in-Aid for Challenging Exploratory Research from Japan Society for the Promotion of Science (No. 21658089).

\section{REFERENCES}

Blackman, V. H. 1919 The compound interest law and plant growth. Ann. Bot., 33: 353-360

Osumi, S. and Y. Ishikawa 1983 Applicability of the Richards' growth function to analysis of growth of tree. The Sci. Rep. Kyoto Pref. Univ. Agric. 35: 49-76

Richards, F. J. 1959 A flexible growth function for empirical use. J. Exp. Bot. 10: 290-300

Shimojo, M., T. Shao, S. Ishimatsu, J. Tanoue, H. Kakihara, C. Sata, H. Fukudome, R. Ishiwaka, Y. Asano, Y. Nakano, M. Tobisa and Y. Masuda 2009 Introducing viewpoints of mechanics into basic growth analysis - (XIII) Comparing growth mechanics between logistic functions and basic growth functions -. J. Fac. Agr., Kyushu Univ., 54: 361-363

Shimojo, M., Y. Nakano, S. Ishimatsu, H. Kakihara, T. Shao and M. Tobisa 2010 Introducing viewpoints of mechanics into basic growth analysis - (XV) Relationships between Richards growth function and basic growth function -. J. Fac. Agr., Kyushu Univ., 55: 259-260 